\title{
A study of facility based management at nutrition rehabilitation centres in Telangana state
}

\author{
S. Vahini, K. Uma Devi and K. Aparna
}

Received: 11.07.2018; Revised: 10.11.2018; Accepted: 24.11.2018

See end of the paper for authors' affiliations

\section{S. Vahini}

Department of Foods and Nutrition, College of Home Science, Professor Jayashankar Telangana State Agricultural University, Saifabad, Hyderabad (Telangana) India

Email : vahinisettypalli@ yahoo.com
ABSTRACT : An observational prospective study was conducted at 12 NRCs in Telangana State, where 60 Severe Acute Malnutrition (SAM) children were recruited. Their sociodemographic details and anthropometric measurements were recorded. These SAM children were followed till the period of 3 follow-up visits to measure their weight. Majority of SAM children belong to rural area, age group less than 3 years, caste OBC (Other Backward Class), ST (Scheduled Tribe) and SC (Scheduled Caste). Outpatient doctors are playing key role in referring them to NRC. Mean scores of weight for age, BMI and MUAC were improved from the time of admission to discharge. Statistical significance found between the mean weight at the time of admission and discharge. Nutritional intervention at NRC decreased the severity of malnourishment among children. NRCs are effective in saving lives of SAM children but not in maintaining long term control on malnutrition.

KEY WORDS: Nutrition rehabilitation centre, Severe acute malnutrition, Body mass index, Mid upper arm circumference

- HOW TO CITE THIS PAPER : Vahini, S., Devi, K. Uma and Aparna, K. (2018). A study of facility based management at nutrition rehabilitation centres in Telangana state. Asian J. Home Sci., 13 (2) : 632-636, DOI: 10.15740/HAS/AJHS/13.2/632-636. Copyright@ 2018: Hind Agri-Horticultural Society. 